\title{
Development of biodegradable methylprednisolone microparticles for treatment of articular pathology using a spray-drying technique
}

This article was published in the following Dove Press journal:

International Journal of Nanomedicine

24 May 2013

Number of times this article has been viewed

\author{
Blanca Tobar-Grande' \\ Ricardo Godoy' \\ Paulina Bustos ${ }^{2}$ \\ Carlos von Plessing' \\ Elias Fattal ${ }^{3,4}$ \\ Nicolas Tsapis ${ }^{3,4}$ \\ Claudia Olave' \\ Carolina Gómez-Gaete' \\ 'Departamento de Farmacia, \\ Facultad de Farmacia, Universidad \\ de Concepción, Concepción, Chile; \\ 2Departamento de Bioquímica \\ Clínica e Inmunología, Facultad de \\ Farmacia, Universidad de Concepción, \\ Concepción, Chile; ${ }^{3}$ Univ Paris-Sud, \\ Institut Galien Paris-Sud, Faculté \\ de Pharmacie, Châtenay-Malabry, \\ France; ${ }^{4}$ CNRS, UMR 86I2, Faculté de \\ Pharmacie, Châtenay-Malabry, France
}

Correspondence: Carolina Gómez Gaete Universidad de Concepción, Facultad de Farmacia, Barrio Universitario S/N,

Concepción, Chile

Fax +564 I2207086

Email cargomez@udec.cl

\begin{abstract}
In this work, microparticles were prepared by spray-drying using albumin, chondroitin sulfate, and hyaluronic acid as excipients to create a controlled-release methylprednisolone system for use in inflammatory disorders such as arthritis. Scanning electron microscopy demonstrated that these microparticles were almost spherical, with development of surface wrinkling as the methylprednisolone load in the formulation was increased. The methylprednisolone load also had a direct influence on the mean diameter and zeta potential of the microparticles. Interactions between formulation excipients and the active drug were evaluated by $\mathrm{x}$-ray diffraction, differential scanning calorimetry, and thermal gravimetric analysis, showing limited amounts of methylprednisolone in a crystalline state in the loaded microparticles. The encapsulation efficiency of methylprednisolone was approximately $89 \%$ in all formulations. The rate of methylprednisolone release from the microparticles depended on the initial drug load in the formulation. In vitro cytotoxic evaluation using THP-1 cells showed that none of the formulations prepared triggered an inflammatory response on release of interleukin- $1 \beta$, nor did they affect cellular viability, except for the $9.1 \%$ methylprednisolone formulation, which was the maximum test concentration used. The microparticles developed in this study have characteristics amenable to a therapeutic role in inflammatory pathology, such as arthritis.
\end{abstract}

Keywords: spray-drying, microparticles, methylprednisolone, chondroitin sulfate, hyaluronic acid, cytotoxic assays

\section{Introduction}

Arthritis is a disease that features joint swelling and/or cartilage erosion, which eventually leads to loss of mobility and deterioration of quality of life. ${ }^{1}$ Currently, there is no curative treatment for the disease, ${ }^{2}$ and the medications available, ie, analgesics or nonsteroidal anti-inflammatory drugs, ${ }^{3}$ disease-modifying antirheumatic drugs, biological therapy, ${ }^{4}$ and glucocorticoids, only mitigate its symptomatology. ${ }^{5}$ Glucocorticoids are the most powerful anti-inflammatory drugs known, and inhibit migration of leukocytes to sites of inflammation by decreasing or inhibiting the action of some of the chemical mediators of inflammation. ${ }^{6}$ Methylprednisolone is often contained in formulations given by intra-articular injection to treat certain types of arthritis, ${ }^{7}$ and there is good evidence to support appropriate use of intra-articular corticosteroids in patients with osteoarthritis of the knee. However, because of the need for multiple intra-articular injections, damage to the cartilage is accelerated. ${ }^{8}$ Therefore, it is essential to develop new formulations of established drugs used in the treatment of inflammatory diseases, allowing sustained drug release to avoid degradation of cartilage and reduce the risk of joint sepsis as a result of repeated injections. 
Development of pharmaceutical microtechnology incorporating drugs and using biodegradable, biocompatible, and nontoxic materials has shown great promise. ${ }^{9}$ Microparticles are a novel therapy in arthritis, because they can act as small reservoir systems for drugs such as methylprednisolone. ${ }^{10}$ The drug release profile depends on various parameters, including size, morphology, porosity, degradability, polymer permeability, and surface features of the active compound. ${ }^{11}$ Another feature of microparticles is their ability to target drugs, in particular those with high toxicity and those having a low therapeutic index, to specific tissues ${ }^{12,13}$ Drug targeting can reduce the number of doses required while increasing the drug concentration at the desired site, thus contributing to a decrease or inhibition of toxic effects. ${ }^{14}$ One of the most original techniques used in the preparation of microparticles is spray-drying, ${ }^{15}$ which has the advantages of being able to be adapted for production on an industrial scale as well as an ability to encapsulate a range of hydrosoluble ${ }^{16}$ and liposoluble (either sensitive or thermoresistant) substances. ${ }^{17}$ The features of the final product, including moisture, particle size, and production yield, are determined by the physicochemical characteristics of the microparticles, as well as by factors such as feed rate, temperature, air flow, and aspirator. ${ }^{17,18}$ Moreover, use of ultrasound in the spray-drying technique helps to streamline the manufacturing process by reducing energy consumption, increasing the yield from the procedure, and avoiding problems such as condensation in the drying chamber. ${ }^{19-21}$

Previous research has established that use of excipients derived from components occurring naturally in the human body improves drug biocompatibility and transport through the usual metabolic pathways. ${ }^{22}$ Albumin has been widely used in the manufacture of microparticles, acting as a vehicle for drug delivery to specific sites..$^{23}$ Hyaluronic acid and chondroitin sulfate are polysaccharides found in the synovial fluid, extracellular matrix, and connective tissue, and have an important role in articular homeostasis. ${ }^{24,25}$ In addition, they have anti-inflammatory and anticatabolic properties that attenuate production of inflammatory mediators by chondrocytes, ${ }^{26}$ as well as having an analgesic action in arthritic joints. ${ }^{27}$ It has also been demonstrated that hyaluronic acid and chondroitin sulfate reduce friction and strain on the articular cartilage. ${ }^{28}$ The pharmacological features of particular excipients have been exploited when devising a matrix for encapsulation of corticosteroids ${ }^{29}$ and disease-modifying agents in the case of arthritic disorders. ${ }^{30}$

The toxicological profile of any microparticle formulation requires evaluation before it can be used safely in human medicine. In vitro cytotoxicity assays compared with animal models enable evaluation of toxicity in a more simple, rapid, and cost-effective way. ${ }^{31}$ Cell viability is the most commonly researched parameter in cytotoxicity tests, and is determined from various cellular processes. ${ }^{31}$ Among the most widely used are the MTT assay which determines mitochondrial function in the cell ${ }^{32}$ and the lactate dehydrogenase release assay which identifies cell membrane damage ${ }^{33}$ or death. ${ }^{34,35}$ Some researchers have shown that microparticles are able to induce an inflammatory response (demonstrated by release of interleukin-1 $\beta$ ) because of the presence of inflammatory precursors, eg, bacteria or endotoxins acquired during the manufacturing process, certain components of the microparticle formulation (eg, polymers, excipients), and wastes produced by the manufacturing process (eg, organic solvents). ${ }^{31}$ In vitro quantification of interleukin- $1 \beta$ is done using the enzymelinked immunosorbent assay, which has become the most frequently used method for quantification of interleukin- $1 \beta$ in supernatants of cell cultures via antibody and enzymatic recognition reactions. ${ }^{36}$

This work describes the manufacture of methylprednisolone microparticles using a spray-drying technique. Both hyaluronic acid and chondroitin sulfate, which are found naturally in the joint cavity, have been used to improve the physical features of spray-dried powders and been found to have the potential to modulate drug release. ${ }^{37,38}$ The aim of this study was to encapsulate methylprednisolone into microparticles, to assess the influence of excipients on in vitro drug release under sink conditions, and to provide a preliminary evaluation of the toxicity of this drug delivery system, given the prospect of its eventual application in the clinical treatment of inflammatory conditions.

\section{Materials and methods Materials}

Bovine serum albumin, hyaluronic acid sodium salt from Streptococcus equi species, chondroitin sulfate sodium salt from bovine trachea, and $N$-(2-hydroxyethyl) piperazine- $N$ ' (2-ethanesulfonic acid) (HEPES) were obtained from SigmaAldrich (St Louis, MO, USA). Methylprednisolone was provided by Spectrum Laboratories Inc (Rancho Dominguez, CA, USA). Ethanol of analytical grade and acetonitrile of high-performance liquid chromatography grade were purchased from Merck (Darmstadt, Germany). Water was purified using an Elga ${ }^{\circledR}$ Purelab Classic UVF system (High Wycombe, UK). The human monocytic cell line THP-1 used in this study was purchased from ATCC (American Type Cell Culture, Manassas, VA, USA). 


\section{Preparation of microparticles}

Biodegradable microparticles containing methylprednisolone were prepared using a spray-drying technique. Briefly, $60 \mathrm{mg}$ albumin, $200 \mathrm{mg}$ of hyaluronic acid, and $340 \mathrm{mg}$ of chondroitin sulfate were dissolved into $140 \mathrm{~mL}$ of water, and methylprednisolone $(4.4,10$, and $60 \mathrm{mg}$, corresponding to $0.73 \%, 1.64 \%$, and $9.1 \%$ by weight) was dissolved into $60 \mathrm{~mL}$ of ethanol. Both solutions were mixed and placed in a mini spray-dryer (B-290, Büchi, Flawil, Switzerland) equipped with a $0.7 \mathrm{~mm}$ two-fluid nozzle. We optimized the process parameters to prevent condensation during spraying, including those that directly affected the final state of the product (eg, spray gas flow and the peristaltic pump, see Table 1). The powdered samples were stored at room temperature under vacuum conditions in a desiccator immediately after spray-drying to limit uptake of moisture in the time interval between production and testing. The yield was computed as a percentage of the mass of powder collected divided by the initial solid mass in the solution prior to spray-drying.

\section{Encapsulation efficiency of methylprednisolone}

First, $11 \mathrm{mg}$ of microparticles containing methylprednisolone $0.73 \%, 1.64 \%$, or $9.1 \%$ were prepared, weighed, and then dissolved in $10 \mathrm{~mL}$ of water by stirring in a vortex mixer (Vortex-Genie $^{\circledR}$, Scientific Industries Inc, Bohemia, NY, USA) at $3200 \mathrm{rpm}$. Next, $10 \mathrm{~mL}$ of acetonitrile containing prednisone as the internal standard was added, then stirred in a vortex mixer at $3200 \mathrm{rpm}$ and sonicated (Sonics and Materials Inc, Newtown, CT, USA) immediately at $80 \%$ amplitude for 2 minutes. One milliliter of the solution obtained was filtered through a $0.22 \mu \mathrm{m}$ polyvinylidene difluoride membrane. The amount of methylprednisolone in the microparticles was determined by injecting $20 \mu \mathrm{L}$ of the filtered solution into a liquid chromatographic column (Merck Hitachi LaChrom Elite L-2130, Merck) equipped with a Rheodyne 7725i injection valve (Sigma-Aldrich)

Table I Optimized parameters for the spray-drying process

\begin{tabular}{lll}
\hline Parameters & Range & Optimal value \\
\hline Inlet temperature $\left({ }^{\circ} \mathrm{C}\right)$ & $100-140$ & 115 \\
Air flow $(\mathrm{L} / \mathrm{h})$ & $283-1052$ & $538 *$ \\
Peristaltic pump $(\mathrm{mL} / \mathrm{min})$ & $6-12$ & 6 \\
Proportions of solvents water: & $70: 30$ & $70: 30$ \\
ethanol $(\mathrm{v} / \mathrm{v})$ & $50: 50$ & \\
& $30: 70$ &
\end{tabular}

Note: $* 100$ psi of pressure. and a programmable ultraviolet absorbance detector (Merck Hitachi LaChrom Elite L-240, Merck). The analysis was carried out at $244 \mathrm{~nm}$ using a reverse phase LiChrosper ${ }^{\mathbb{B}}$ C18 column $(5 \mu \mathrm{m}, 250 \times 4.0 \mathrm{~mm}$, Merck) with a solvent mixture of $40 \%$ acetonitrile and $60 \%$ water delivered isocratically at a flow rate of $1 \mathrm{~mL}$ per minute. All analyses were performed at ambient temperature (approximately $23^{\circ} \mathrm{C}$ ). The method developed showed suitable linearity between $0.2 \mu \mathrm{g} /$ $\mathrm{mL}$ and $624 \mu \mathrm{g} / \mathrm{mL}\left(\mathrm{y}=0.0523 \mathrm{x}+0.0107\right.$; with $\left.\mathrm{r}^{2}=1\right)$. Encapsulation efficiency for the methylprednisolone-loaded particles (MP-EE) was expressed as w/w \%:

$$
\mathrm{MP}-\mathrm{EE}=\frac{\mathrm{MP}_{\text {micro }}}{\mathrm{MP}_{0}} \times 100
$$

Where, $\mathrm{MP}_{\text {micro }}=$ Total amount of methylprednisolone in microparticles. $\mathrm{MP}_{0}=$ Initial amount of methylprednisolone.

\section{Scanning electron microscopy}

Scanning electron microscopy was performed using a JEOLJSM 6380 LV instrument (JEOL Techniques Ltd, Tokyo, Japan) furnished with an Inca X-Sight 7582 (Oxford Instruments, Abingdon, UK) operating at a $20 \mathrm{kV}$ accelerating voltage. The microparticles were coated with a gold layer of about $150 \AA$ thickness, using an Edwards S 150 sputter coater (Agar Scientific, Standsted, UK).

\section{Zeta potential and particle size}

The zeta potential was measured using a Malvern Zetasizer Nano ZS (Malvern Instruments, Worcestershire, UK) based on quasi-elastic light scattering at $25^{\circ} \mathrm{C}$ following $1 / 50(\mathrm{v} / \mathrm{v})$ dilution in a $1 \mathrm{mM} \mathrm{NaCl}$ solution. The values reported represent the average of three measurements. The size distribution of the powder was measured by light diffraction using a Mastersizer 2000 equipped with a Scirocco dry dispenser (Malvern Instruments, Orsay Cedex, France) at a dispersing pressure of 2 bar. Each sample was measured in triplicate. Data are expressed in terms of the particle diameter, at $10 \%$, $50 \%$, and $90 \%$ of volume distribution (D10, D 50 , and D 90 , respectively). The volume distribution span, which is the distribution width measurement relative to the median diameter, was calculated as follows:

$$
\text { Span }=\frac{\mathrm{D} 90-\mathrm{D} 10}{\mathrm{D} 50}
$$

\section{X-ray diffraction}

X-ray powder diffraction patterns were measured using a D4 Endeavor $^{\circledR}$ diffractometer (Bruker, Billerica, MA. USA) with $\mathrm{Ni}$-filtered $\mathrm{Cu} \mathrm{K} \alpha_{1}$ radiation while being operated at $40 \mathrm{kV}$ 
and $20 \mathrm{~mA}$. The step width was $0.02^{\circ}$, with a one second counting time per step. Samples were run between $3^{\circ}$ and $50^{\circ} 2 \theta$.

\section{Differential scanning calorimetry}

The microparticles were analyzed in aluminum pans using a differential scanning calorimeter $(\mathrm{GmbH} 822 \mathrm{e}$, Mettler Toledo, Columbus, OH, USA) furnished with a EK90/MT type Thermo Haake intracooler (Sigma-Aldrich, St Gallen, Switzerland). Differential scanning calorimetry runs were conducted under a nitrogen atmosphere flow rate of $20 \mathrm{~mL}$ per minute, while temperature ranged from $25^{\circ} \mathrm{C}$ to $300^{\circ} \mathrm{C}$, at a heating rate of $5^{\circ} \mathrm{C}$ per minute.

\section{Thermogravimetric analysis}

Thermogravimetric analysis was carried out using an STA 449 F3 Jupiter ${ }^{\circledR}$ device (Netzsch-Gerätebau GmbH, Selb, Germany). Sample weights ranged from $10 \mathrm{mg}$ to $15 \mathrm{mg}$. The sample pan was placed in the balance system while the temperature was increased from $25^{\circ} \mathrm{C}$ to $100^{\circ} \mathrm{C}$ at a heating rate of $5^{\circ} \mathrm{C}$ per minute. The sample pan weight was recorded continuously.

\section{In vitro drug release study}

In vitro release of methylprednisolone from the microparticles was studied under sink conditions, whereby the drug concentration in the total medium was kept 10 times lower than the solubility of saturated methylprednisolone in HEPES buffer $(120 \mu \mathrm{g} / \mathrm{mL})$. A weighed amount of microparticles equivalent to about $3 \mathrm{mg}$ of methylprednisolone was resuspended in $10 \mathrm{~mL}$ of $10 \mathrm{mM}$ HEPES buffered saline $(150 \mathrm{mM}$ $\mathrm{NaCl}, \mathrm{pH}$ 7.4) by means of vortexing, then put into a dialysis tube (molecular weight cutoff 12,000 Da, Sigma Chemical Corporation, St Louis, MO, USA). The dialysis tube was then placed inside a $300 \mathrm{~mL}$ glass bottle containing $240 \mathrm{~mL}$ of HEPES buffered saline. A release test was performed at $37^{\circ} \mathrm{C}$, with a $100 \mathrm{rpm}$ stirring rate on a Multistirred $6^{\circledR}$ (Velp Scientifica, Milan, Italy). At predetermined time intervals, $1.0 \mathrm{~mL}$ aliquots were withdrawn from the outer aqueous solution and replaced by a similar volume of fresh medium. The methylprednisolone released was quantified by highperformance liquid chromatography. Each in vitro release experiment was repeated three times.

\section{In vitro cytotoxic assays}

\section{Cell viability assay}

The cell growth rate was assessed using a commercially available Vybrant ${ }^{\circledR}$ MTT cell proliferation assay Kit (Invitrogen, Carlsbad, CA, USA). Briefly, THP-1 cells were suspended at a final concentration of $1 \times 10^{6}$ cells $/ \mathrm{mL}$ in growth medium consisting of RPMI-1640 supplemented with 10\% heat-inactivated fetal bovine serum, 1\% L-glutamine, $1 \%$ of $100 \mathrm{mM}$ sodium pyruvate, $1 \%$ of $1 \mathrm{M}$ HEPES, $1 \%$ of $1.4 \mathrm{M}$ glucose, $0.1 \%$ of $0.05 \mathrm{mM}$ 2-mercaptoethanol and $1 \%$ penicillin-streptomycin.

$$
\% \text { cell viability }=\frac{\text { Absorbance in sample }}{\text { Absorbance in control }} \times 100
$$

\section{Membrane damage assay}

Lactate dehydrogenase release was measured to quantify membrane damage using a cytotoxicity detection kit (LDH12 Cobas CIII, Roche, Germany). Briefly, THP-1 cells were seeded into 24-well plates $\left(1 \times 10^{6}\right.$ cells/well $)$. After exposure to increasing microparticle concentrations $(0.02-5 \mathrm{mg} / \mathrm{mL})$, the culture supernatants were removed and centrifuged at $5000 \mathrm{rpm}$ for 5 minutes to remove cell debris and microparticles. Next, $1 \times 10^{6}$ cells were subjected to sonication for one minute at 130 Watts as a control for total lysis. The lactate dehydrogenase released was measured (ie, total lysis control) and then used as an index of cellular membrane integrity, as follows:

$\%$ LDH release $=\frac{\text { LDH in sample }- \text { LDH } 0 \%}{\text { LDH } 100 \%-\text { LDH } 0 \%} \times 100$

where "LDH in sample" is the lactate dehydrogenase released into the external medium, "LDH $0 \%$ " is the amount of lactate dehydrogenase present in the culture medium, and "LDH $100 \%$ " is the lactate dehydrogenase released after sonication, corresponding to $100 \%$ cell lysis.

\section{Enzyme-linked immunosorbent assay for interleukin-I $\beta$ quantification}

An in vitro study of interleukin- $1 \beta$ quantification was performed on cells exposed to suspensions containing different microparticle concentrations $(0.02-5 \mathrm{mg} / \mathrm{mL})$, either unloaded and loaded with $1.64 \%$ or $9.1 \%$ microparticles, using a commercially available human interleukin- $1 \beta$ enzyme-linked immunosorbent assay kit (Ready-SET-Go! ${ }^{\circledR}$, eBioscience Inc, San Diego, CA, USA), following the manufacturer's instructions. The optical density from the individual wells was measured using a spectrophotometer at $450 \mathrm{~nm}$ (Bio-Tek Instruments Inc). The assay quantification limit was $7.8 \mathrm{pg} / \mathrm{mL}$.

\section{Results and discussion}

Microparticles containing methylprednisolone were formulated by spray-drying and evaluated to determine the influence of excipients on in vitro drug release under sink 
conditions and to assess the toxicity of this method of drug delivery in THP-1 cells, considering their potential for use in the clinical treatment of inflammatory disorders.

\section{Optimization of formulation parameters}

The formulation parameters were optimized by modifying the ratios and concentrations of the components (ie, albumin, chondroitin sulfate, and hyaluronic acid) in the spraying solution (200 mL water:ethanol 70:30 v:v mixture). The morphology of the microparticles was assessed by scanning electron microscopy (Figure 1). When the microparticles were produced only with albumin, they were found to be polydispersed and oval with a rough surface, especially those that were of the smallest sizes (Figure 1A). From this formulation, microparticles containing $67 \%$ albumin and $33 \%$ chondroitin sulfate were produced, which showed markedly superior morphological characteristics, becoming less rough and being semispherical (Figure 1B). A similar morphology was achieved by adding $33 \%$ hyaluronic acid to the $67 \%$ albuminbased formulation. A marked increase in diameter was found in these microparticles, demonstrating that the presence of albumin contributes to their oval shape and surface texture (Figure 1C). Therefore, the decision was made to produce microparticles containing smaller amounts of albumin and an increased chondroitin sulfate content (10\% albumin, 33\% hyaluronic acid, $57 \%$ chondroitin sulfate). The final microparticle preparation had improved morphological features, with a spherical shape and an almost smooth surface (Figure 1D).

\section{Optimization of process parameters}

Once the composition and ratio of the excipients composing the microparticle matrix were established, optimization of
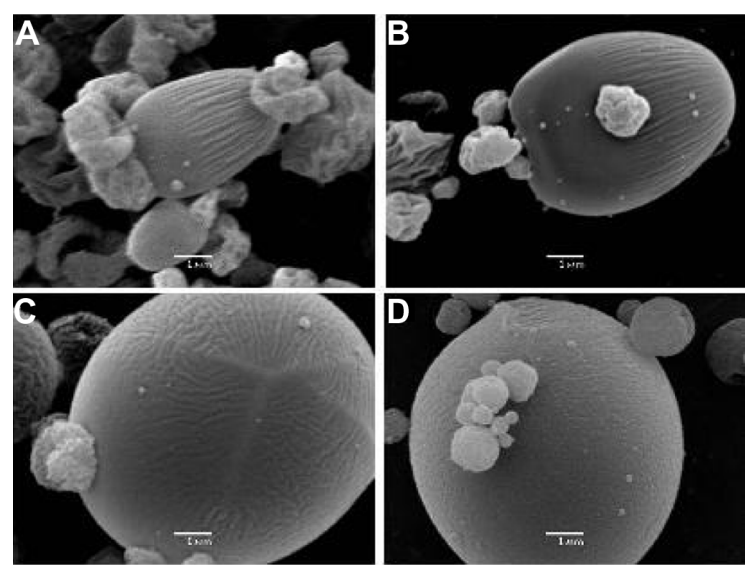

Figure I Microparticles obtained by varying the components of the formulation (A) Albumin $6 \mathrm{~g} / \mathrm{L}$, (B) albumin at $67 \%$ and chondroitin sulfate at $33 \%, 3 \mathrm{~g} / \mathrm{L}$, (C) albumin at $67 \%$ and hyaluronic acid at 33\%, $3 \mathrm{~g} / \mathrm{L}$, and (D) albumin at $10 \%$, hyaluronic acid at $33 \%$, and chondroitin sulfate at $57 \%, 3 \mathrm{~g} / \mathrm{L}$. the manufacturing equipment parameters was carried out (Table 1). These parameters were adjusted to prevent condensation in the drying chamber, and to optimize particle characteristics, such as particle size, which directly affects the status of the final product. It was observed that when the feed rate was increased by means of a peristaltic pump, condensation took place within the equipment drying chamber. Therefore, a value of $6 \mathrm{~mL}$ per minute was set..$^{39}$ In addition, inlet temperatures lower than $115^{\circ} \mathrm{C}$ and an ethanol ratio in aqueous solution lower than $30 \%$ generated a decrease in outlet temperature and, consequently, condensation inside the drying chamber. ${ }^{40}$

Recent research has shown that submicron-sized microparticles are taken up rapidly by phagocytic cells in the synovium, whereas microspheres ranging in size from $3 \mu \mathrm{m}$ to $60 \mu \mathrm{m}$ remain dispersed in the joint cavity or adherent to the surface of the synovial membrane, and are well tolerated. However, microspheres in the smaller size range trigger a marked inflammatory response, causing joint swelling and loss of proteoglycans. ${ }^{41}$ In order to produce particles with an optimum mean diameter $(3-60 \mu \mathrm{m})$ it was necessary to reduce the spraying air flow rate, setting $538 \mathrm{~L}$ per hour as the lower limit, given that lower flow rates led to condensation inside the drying chamber.

Once the process parameters were optimized, different amounts of methylprednisolone were included with the aim of producing microparticles loaded with different concentrations of active drug $(0.73 \%, 1.64 \%$, and $9.1 \%)$, along with the excipients sprayed in the 70:30 water:ethanol mixture. Figure 2 shows the influence of methylprednisolone load on the morphology and size of the microparticles. All the microparticles maintained their spherical shape, but their surface roughness increased in direct proportion to the concentration of methylprednisolone in the formulation. Previous research has reported that the surface characteristics of microparticles do not affect cell attachment, proliferation, or uniform distribution in cells. ${ }^{42}$

\section{Encapsulation efficiency for methylprednisolone}

The encapsulation efficiency for methylprednisolone was rather high, ranging from $89.20 \%$ to $95.43 \%$ for all the microparticles produced (Table 2 ), with a statistically significant difference $(P<0.05)$ in the highest values for drug entrapment achieved when working with a $1.64 \%$ methylprednisolone concentration. Nevertheless, it was noted that there was no statistically significant difference in encapsulation efficiency for the process yield according 


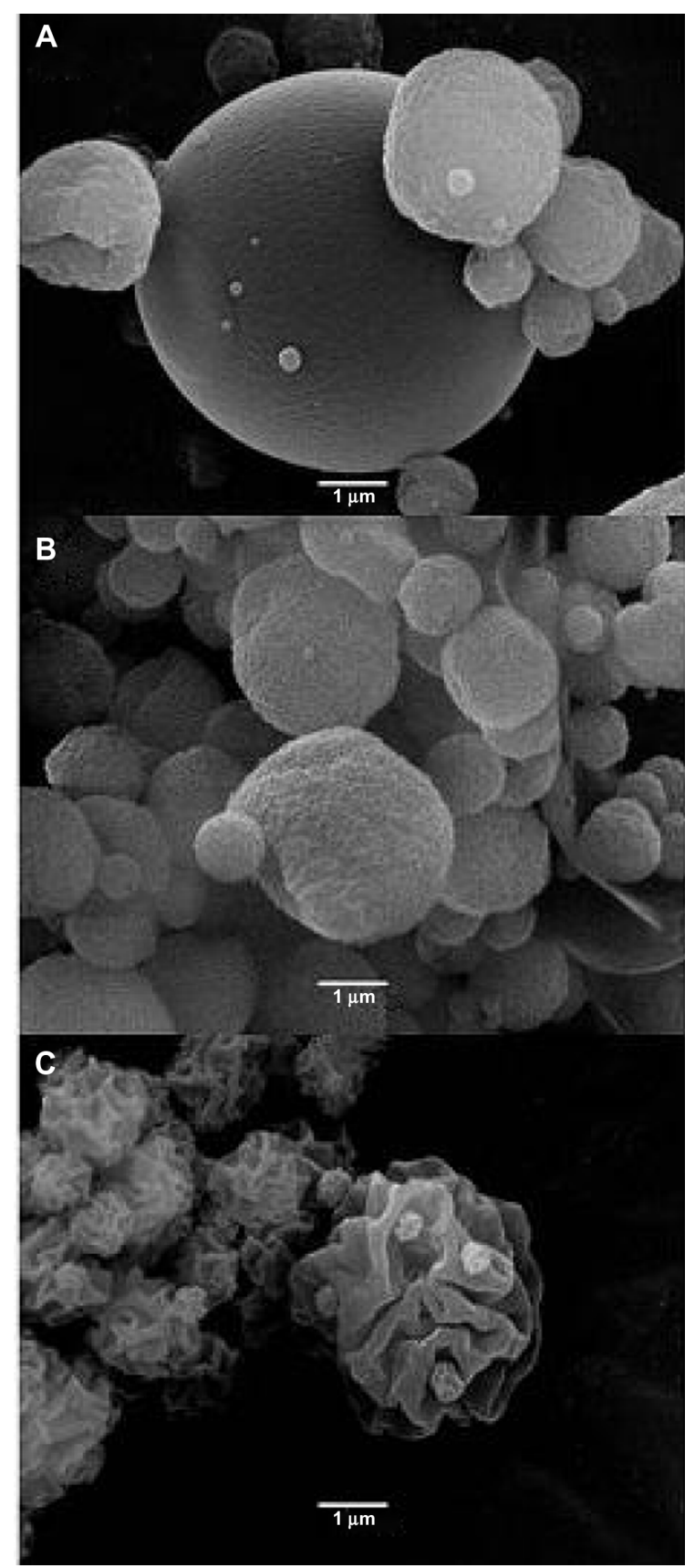

Figure 2 Methylprednisolone-loaded microparticles at concentrations of (A) $0.73 \%$, (B) $1.64 \%$, and (C) $9.1 \%$.

to methylprednisolone concentration $(P>0.999)$. Indeed, previous studies have reported that the spray-drying process provides a fairly high encapsulation efficiency compared with other methods, such as solvent emulsion/evaporation. ${ }^{43}$

\section{Particle size and zeta potential}

Table 3 shows the particle sizes for the unloaded and loaded microparticles. Statistical analysis showed a meaningful difference $(P<0.05)$ between the mean diameters ([D50]).
All microparticles showed a bimodal size distribution, thus having a huge population, most likely caused by aggregation of particles as a result of fusion or melting during the final stages of the drying process. ${ }^{44}$ The agglomerates were not completely broken down, in spite of the dispersion pressure ( 2 bar) used in the laser diffraction equipment. However, aggregation of microparticles loaded with methylprednisolone $9.1 \%$ was found to be decreased, with a mean diameter (D50) of $16.73 \mu \mathrm{m}$, similar to what was observed by scanning electron microscopy (Figure 2). This decrease in aggregation can be explained by the surface roughness, which decreases the forces existing between the particles. ${ }^{16,45}$ Earlier studies of dexamethasone encapsulation showed that changes in particle size distribution can be due to particle aggregation, such that both the mean and median sizes increased steeply as more dexamethasone was incorporated into the formulation, with the size increase being greater at higher dexamethasone concentrations. ${ }^{29}$

The zeta potential for all formulations was found to be negative, from -48 to $-35 \mathrm{mV}$, with the zeta potential becoming less negative as the concentration of methylprednisolone increased, possibly because of the contribution to neutrality provided by the active principle. In spite of this, it is believed that such an order of magnitude promotes repulsion among particles, keeping them as individual entities when dispersed in water. This suggests formation of flocculated and stable suspensions in aqueous medium, which, in turn, build up noncompacted aggregates that are easy to resuspend by the time they settle. ${ }^{46}$

\section{Structural and thermal analysis}

The physical state of the drug contained in the microparticles was established by crystallographic analysis using $\mathrm{x}$-ray diffraction. Figure 3 shows the x-ray diffraction patterns for the individual components of the formulations, physical mixtures, and microparticles. Typical peaks are observed in the methylprednisolone diffraction pattern, indicating their crystalline nature, while albumin, hyaluronic acid, and chondroitin sulfate show a mainly shapeless structure with limited crystal-

Table 2 Encapsulation efficiency of methylprednisolone in the microparticles $(n=8)$ and percentage yield of the process $(n=3)$

\begin{tabular}{lll}
\hline $\begin{array}{l}\text { Microparticles } \\
\text { (MP) }\end{array}$ & $\begin{array}{l}\text { Encapsulation efficiency } \\
\text { of methylprednisolone (\%) }\end{array}$ & $\begin{array}{l}\text { Yield of the } \\
\text { process (\%) }\end{array}$ \\
\hline Unloaded & - & $37.1 \pm 6.7$ \\
MP at $0.73 \%$ & $91.48 \pm 26.35$ & $37.7 \pm 2.4$ \\
MP at $1.64 \%$ & $95.43 \pm 10.70$ & $38.0 \pm 6.5$ \\
MP at $9.10 \%$ & $89.20 \pm 6.46$ & $33.7 \pm 5.0$ \\
\hline
\end{tabular}


Table 3 Particle size and zeta potential of microparticles $(n=3)$

\begin{tabular}{|c|c|c|c|c|c|}
\hline \multirow[t]{2}{*}{ Microparticles } & \multicolumn{3}{|c|}{ Diameters $(\mu \mathrm{m}) \pm \mathrm{SD}$} & \multirow[t]{2}{*}{ Span } & \multirow{2}{*}{$\begin{array}{l}\text { Zeta potential } \\
(\mathrm{mV}) \pm \mathrm{DS}\end{array}$} \\
\hline & DIO & D50 & D90 & & \\
\hline Unloaded & $2.34 \pm 0.08$ & $23.29 \pm 0.96$ & $59.77 \pm 1.99$ & 2.47 & $-48.33 \pm 3.28$ \\
\hline MP at $0.73 \%$ & $2.11 \pm 0.06$ & $31.43 \pm 0.18$ & $81.24 \pm 0.06$ & 2.52 & $-46.70 \pm 3.97$ \\
\hline MP at $1.64 \%$ & $2.09 \pm 0.00$ & $32.72 \pm 0.32$ & $86.01 \pm 1.36$ & 2.56 & $-36.37 \pm 4.56$ \\
\hline MP at $9.10 \%$ & $1.59 \pm 0.02$ & $16.73 \pm 0.12$ & $53.08 \pm 0.14$ & 3.08 & $-35.60 \pm 7.64$ \\
\hline
\end{tabular}

Abbreviation: SD, standard deviation.

linity (Figure 3A). With respect to the physical mixtures of the components of the formulation prepared using the same ratios as in the manufactured microparticles, methylprednisolone was observed to be present in a crystalline form, for which the peaks in intensity were proportional to the concentration of the active principle found in each mixture (Figure 3B). However, the characteristic peaks of methylprednisolone were not seen in the manufactured microparticles. In spite of this, the intensity of the signal increased proportionally to the methylprednisolone concentration loaded into the microparticles, which was not seen in the empty microparticles (Figure 3C). Such a signal may be attributable to the structural rearrangement undergone by components of the microparticles during the manufacturing process, indicating some modifications to their crystalline configuration. Nevertheless, the intensity
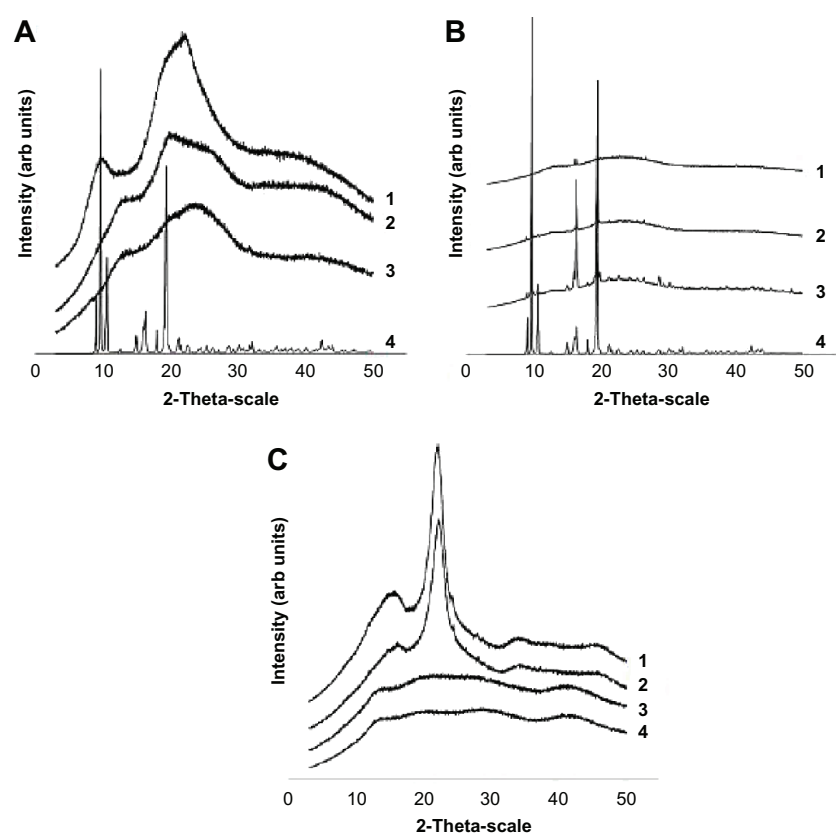

Figure 3 (A) X-ray diffraction patterns for the formulation components including (I) albumin, (2) hyaluronic acid, (3) chondroitin sulfate, and (4) methylprednisolone. (B) Physical mixtures of the formulation components, including (I) methylprednisolone $0.73 \%$, (2) methylprednisolone $1.64 \%$, (3) methylprednisolone $9.1 \%$, and (4) compared with methylprednisolone. (C) Methylprednisolone-loaded microparticles at (I) $9.1 \%$, (2) $1.64 \%$, (3) $0.73 \%$, and (4) comparison with unloaded microparticles. of the peak generated is linked to the presence of methylprednisolone in a crystalline state.

The physical state of the drug when encapsulated in microparticles was further established by differential scanning calorimetry. Figure 4 shows the thermograms obtained for the components of the formulation. Chondroitin sulfate and hyaluronic acid have endothermic peaks within the temperature range of $50^{\circ} \mathrm{C}-150^{\circ} \mathrm{C}$, which may reflect loss of the volatile components. ${ }^{47}$ Further, the thermogram for chondroitin sulfate shows an exothermic peak at $231^{\circ} \mathrm{C}$, while hyaluronic acid shows two exothermic peaks at $227^{\circ} \mathrm{C}$ and $243^{\circ} \mathrm{C}$, respectively, which are attributable to degradation of these polysaccharides. ${ }^{24,47}$ The methylprednisolone thermogram shows an endothermic transition at $220^{\circ} \mathrm{C}$ and an endothermic melting peak at $238^{\circ} \mathrm{C}$ (Figure $4 \mathrm{~A}$ ). ${ }^{48}$ However, differential scanning calorimetry curves for all the microparticle preparations show an endothermic peak typical of albumin denaturation, as well as an exothermic peak at $221^{\circ} \mathrm{C}$ possibly due to degradation or decomposition of the component resulting from the formulation excipients molecular crossing-over (Figure 4B). This same exothermic peak was seen for the physical mixtures of the separate components in proportions similar to those used in the microparticles (Figure 4C).

Given that the behavior found in the differential scanning calorimetry patterns generated by all microparticles and physical mixtures of the formulation components was the same, a thermogravimetric analysis was undertaken for microparticles prepared with a methylprednisolone concentration of $9.1 \%$, together with an assessment of that process due to the exothermic peak seen at $221^{\circ} \mathrm{C}$. The thermogravimetric pattern showed a loss of mass from the initial weight of the settled microparticles, with a point of inflection in the curve generated at the same temperature as that which had been observed in the exothermic peak at $221^{\circ} \mathrm{C}$ which became obvious in the differential scanning calorimetry thermogram. All these findings point to this peak being generated via a degradation or decomposition process. ${ }^{49}$ Structural characterization of the microparticles 

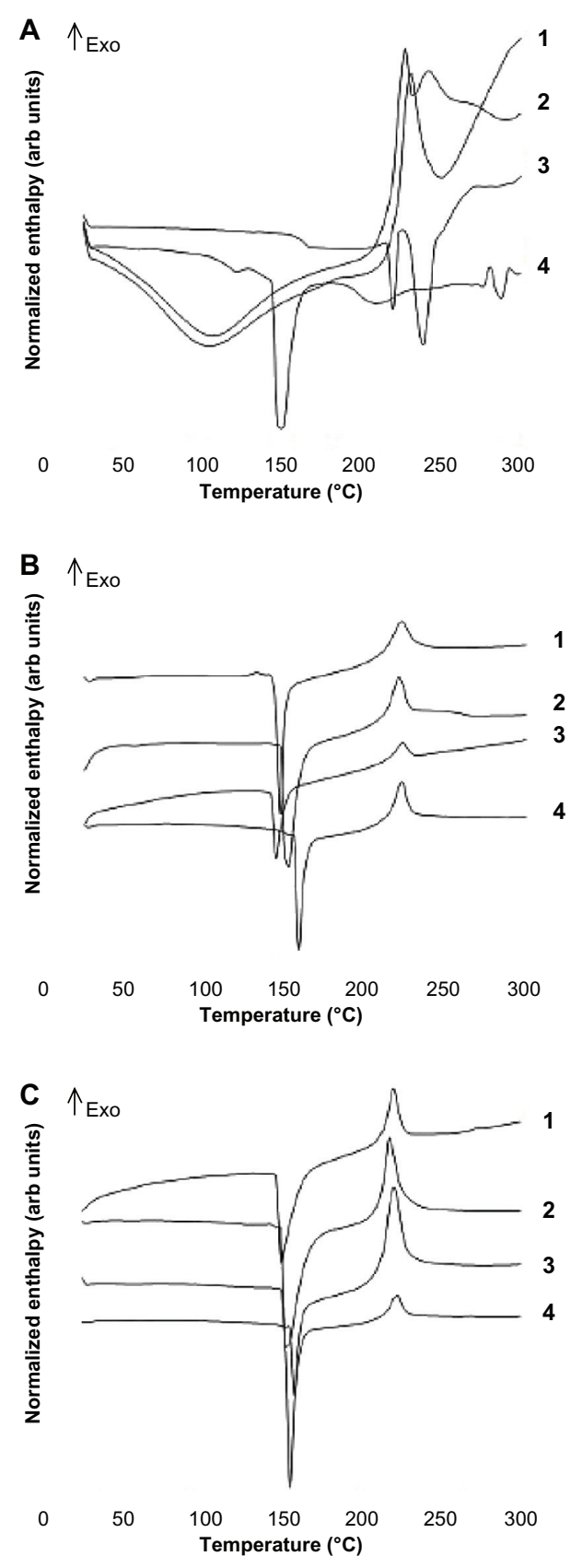

Figure 4 (A) Differential scanning calorimetry curves for the formulation components, ie, (I) chondroitin sulfate, (2) hyaluronic acid, (3) methylprednisolone, and (4) albumin. (B) Methylprednisolone-loaded microparticles at concentrations of (I) $9.1 \%$. (2) $1.64 \%$, (3) $0.73 \%$, and (4) unloaded microparticles. (C) Physical mixtures of the formulation components, including (1) methylprednisolone $9.1 \%$, (2) methylprednisolone $1.64 \%$, (3) methylprednisolone $0.73 \%$, and (4) comparison with unloaded microparticles.

clearly shows an interaction between the components of the formulation as well as adequate molecular dispersion of the drug within the microparticle matrix.

\section{In vitro drug release from microparticles}

The amount of methylprednisolone released from the microparticles was calculated on the basis of the actual amount of methylprednisolone encapsulated inside the microparticles. Figure 5 shows the release of methylprednisolone from the microparticles under sink conditions. As expected, diffusion of free methylprednisolone from the dialysis bag was faster and complete after 8 hours, as compared with the methylprednisolone-loaded microparticles, all of which showed a biphasic pattern that consisted of a burst release within the first 4 hours, followed by a slower and more steady release phase (Figure 5A). This burst release may be due to the fact that the active principle is linked to the surface or embedded in the external layers of the microparticles. ${ }^{50}$ The maximum drug release from the microparticles loaded with methylprednisolone $0.73 \%$ was $94 \%$ after 4 days of incubation. However, for the same incubation period, the maximum drug release for methylprednisolone encapsulated at $1.64 \%$ was $90 \%$, while that for methylprednisolone encapsulated at $9.1 \%$ was just $65 \%$ (Figure 5B). When the incubation time was extended to 25 days, $80 \%$ drug release was observed for the latter formulation (Figure 5C).

Our release kinetics study demonstrated that microparticles act as reservoirs, maintaining constant release of the active principle according to incubation time, despite the fact that the components of the microparticle formulation are water-soluble. ${ }^{10}$ The ability of hyaluronic acid and chondroitin sulfate to thicken enables formation of a gelled structure with which the drug interacts and in which it remains trapped, thus delaying its release. ${ }^{25}$ After 25 days of incubation, the microparticles remaining in the dialysis membrane were observed by scanning electron microscopy (Figure 6). It can be seen that they maintained their spherical shape after the components were hydrated, with the presence of pores or channels in the surfaces of the microparticle. Such pores or channels may develop when methylprednisolone is being released. ${ }^{50}$

It is known that drug release from microparticles in vivo depends on the quantity and composition of the fluid, and its rate of exchange or replenishment. However, the results of our study provide information about the behavior of such a system in a biological fluid environment for a specific period of time. In fact, when compared with the control, it was demonstrated that, even under sink conditions, microparticles may retard the release of methylprednisolone which probably has biological transcendence in a future in vivo release study.

\section{In vitro cytotoxic assays}

After the microparticles were prepared and characterized, those with the highest methylprednisolone loads were 

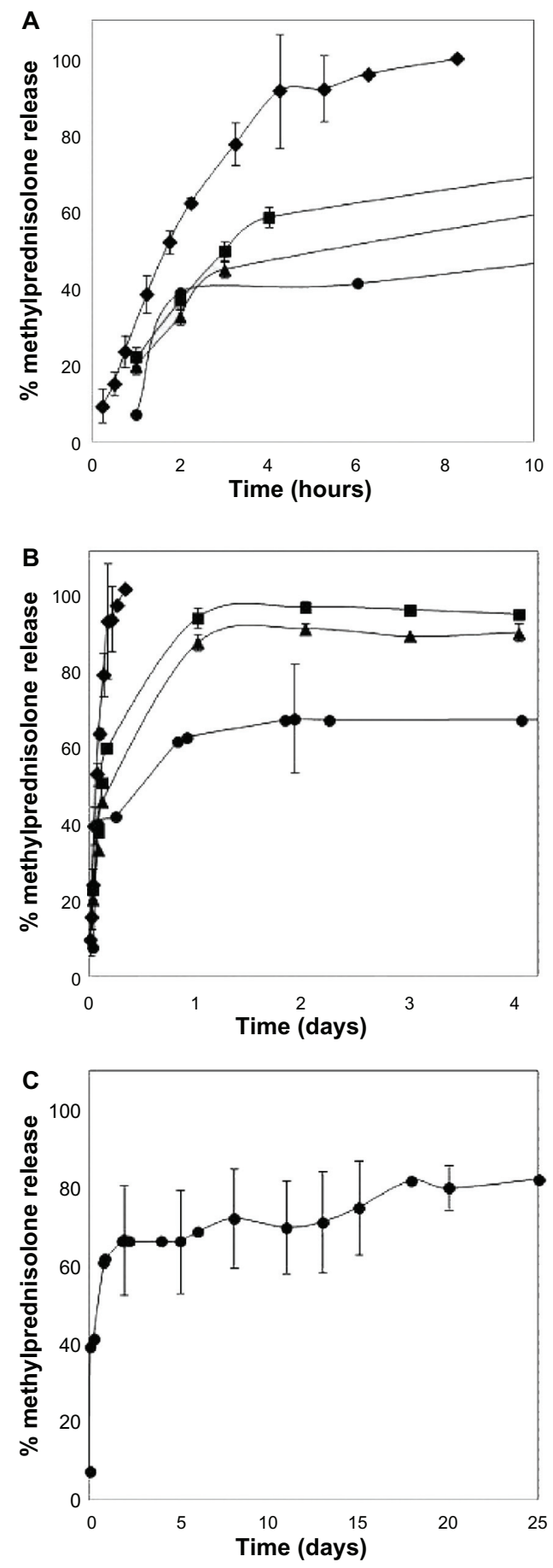

Figure 5 Kinetics of methylprednisolone diffusion in HEPES buffer ( $\mathrm{pH}$ 7.4) under sink conditions $(\bullet)$ and in vitro release profile of methylprednisolone from microparticles, in turn including $(\square)$ methylprednisolone $0.73 \%,(\boldsymbol{\Delta})$ methylprednisolone I.64\%, and (•) methylprednisolone $9.1 \%$ kept in release medium for (A) 10 hours, (B) 4 days and (C) 25 days. Data represent the mean \pm standard deviation $(n=2)$.

chosen $(1.64 \%$ and $9.1 \%)$ for the in vitro cytotoxicity assays conducted in THP-1 cell cultures, with 24 hours and 48 hours of exposure time, and at different concentrations $(0.02-5 \mathrm{mg} / \mathrm{mL})$ of microparticle suspension. The same procedure was followed for the empty microparticles.

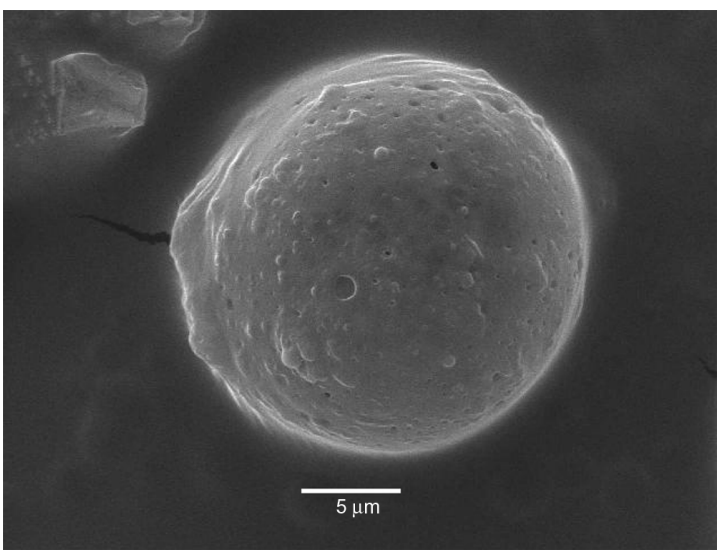

Figure 6 Scanning electron microscopic image of a typical microparticle loaded with methylprednisolone $9.1 \%$ after an in vitro release study (25 days).

\section{Cell viability assay}

According to our MTT assay (Figure 7), the THP-1 cells maintained $100 \%$ viability after 24 hours of exposure to all concentrations of the empty control microparticles, except for the $5 \mathrm{mg} / \mathrm{mL}$ concentration, where $66 \%$ viability was recorded. On the other hand, THP-1 cells that had been exposed to different microparticle concentrations containing methylprednisolone $1.64 \%$ also showed a marked decrease in cell viability of $75 \%$ with the $5 \mathrm{mg} / \mathrm{mL}$ concentration. When microparticles containing methylprednisolone 9.1\% were used at a $5 \mathrm{mg} / \mathrm{mL}$ concentration, cell viability showed a statistically significant decrease of about $40 \%(P<0.05)$. Similar results for THP-1 cell viability were obtained after 48 hours of culture, with $0 \%$ cellular viability reached at a microparticle concentration of $5 \mathrm{mg} / \mathrm{mL}$.

\section{Membrane damage assay}

The potential of the microparticle formulations to be toxic to the cell membrane was evaluated using the lactate dehydrogenase assay (Figure 8). THP-1 cell cultures exposed to different concentrations $(0.02-5 \mathrm{mg} / \mathrm{mL})$ of unloaded microparticles did not show any lactate dehydrogenase release after a 24-hour exposure period, indicating no membrane damage. However, cultures exposed to different concentrations of microparticles containing methylprednisolone $1.64 \%$, showed increased release of lactate dehydrogenase, reaching $20 \%$ with the $5 \mathrm{mg} /$ $\mathrm{mL}$ concentration. When using microparticles containing methylprednisolone $9.1 \%$, release of lactate dehydrogenase also showed a statistically significant increase, reaching $47 \%$ for the $5 \mathrm{mg} / \mathrm{mL}$ concentration $(P<0.05)$. Similar trends were observed after 48 hours of culture, with lactate dehydrogenase release reaching $100 \%$ for microparticles 


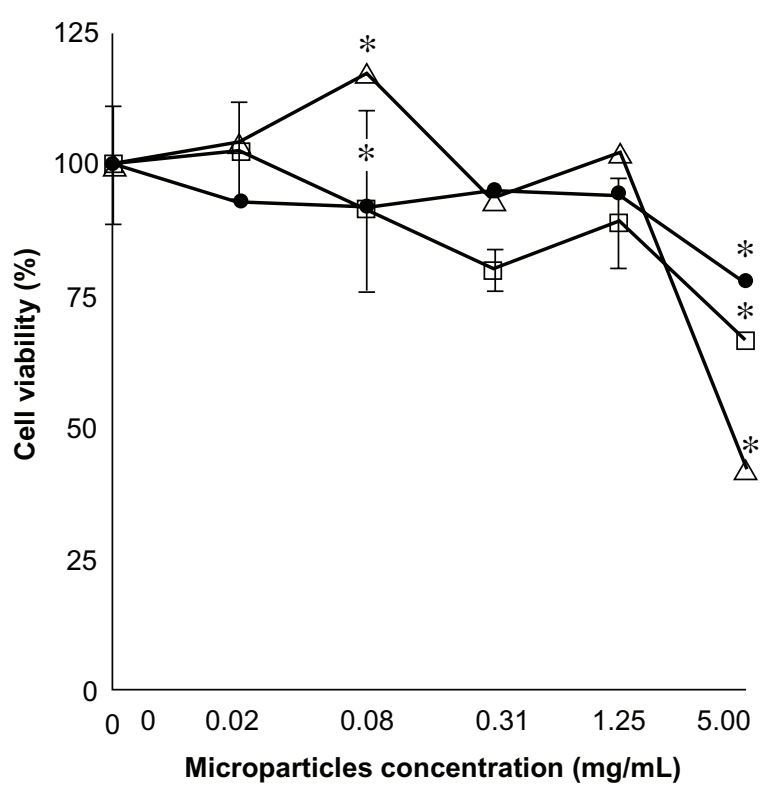

Figure 7 Percentage cell viability found by MTT assay of a THP-I cell exposed to different concentrations over 24 hours. ( $\square$ ) Unloaded microparticles, $(\bullet)$ microparticles loaded with methylprednisolone $1.64 \%,(\Delta)$ and methylprednisolone 9.1\% $(n=2) \pm$ standard deviation.

Note: *Significant difference, $P<0.05$.

containing methylprednisolone $9.1 \%$ at a microparticle concentration of $5 \mathrm{mg} / \mathrm{mL}$.

Previous studies evaluating the effect of methylprednisolone on the cell cycle showed that exposure to high corticosteroid concentrations exerts a negative effect on osteoblasts

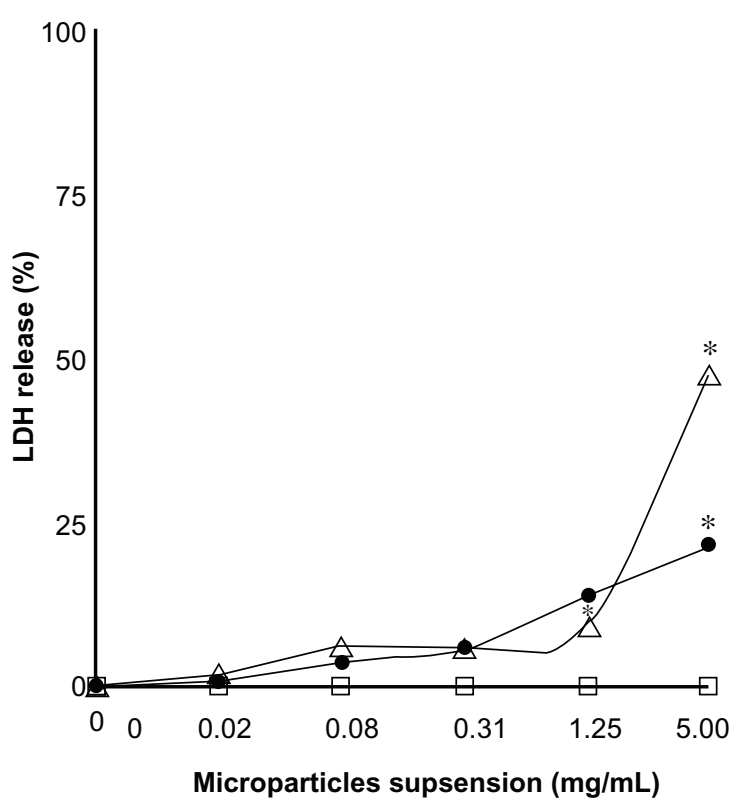

Figure 8 Percentage of lactate dehydrogenase release found by lactate dehydrogenase assay for a THP-I cell exposed to different concentrations over 24 hours. $(\square)$ Unloaded microparticles, $(\bullet)$ microparticles loaded with methylprednisolone I.64\%, and $(\Delta)$ and methylprednisolone $9.1 \%(n=2) \pm$ standard deviation. Note: *Significant difference, $P<0.05$. by hindering their proliferation. ${ }^{51}$ Likewise, similar studies have shown that high corticosteroid doses inhibit synthesis of proteoglycans and also negatively affect the structural arrangement of collagen within cartilage. ${ }^{52}$ These studies provided the basis for the effect we observed, ie, a decrease in proliferation capacity and viability when THP-1 cells were exposed to high concentrations $(5 \mathrm{mg} / \mathrm{mL})$ of the methylprednisolone $9.1 \%$ formulation, in turn linked to damage to the functional organelles of the cell or to destabilization or disruption of the cell membrane. However, some studies have shown that materials that lead to a viability greater than $80 \%$ are considered as biocompatible, ${ }^{53}$ so it can be concluded that microparticles manufactured to contain only the matrix, as well as those ones loaded with methylprednisolone $16.4 \%$ and 9.1\%, do not exert toxic effects on THP-1 cells at microparticle concentrations below $1.25 \mathrm{mg} / \mathrm{mL}$.

\section{Inflammatory response}

The inflammatory response was determined by quantification of the amount of interleukin- $1 \beta$ present in the supernatant of THP-1 cell cultures exposed to different microparticle concentrations $(0.02-5 \mathrm{mg} / \mathrm{mL})$, none of which was able to induce release of interleukin-1 $\beta$ from THP-1 cells at concentrations similar to or higher than $7.8 \mathrm{pg} / \mathrm{mL}$ (minimum concentration for quantification). A literature review has shown that interleukin-1 $\beta$ levels in normal serum are below $15 \mathrm{pg} / \mathrm{mL},{ }^{54}$ whereas levels associated with a number of infectious diseases and noninfectious inflammatory diseases, such as Crohn's disease, are higher than this level. ${ }^{55}$ Increased interleukin-1 $\beta$ levels have also been found in the synovial fluid of patients with rheumatoid arthritis. ${ }^{56}$ Other studies have confirmed these findings, indicating that one of the mechanisms of action explaining the anti-inflammatory effect of corticosteroids is inhibition of interleukin- $1 \beta$ production..$^{57,58}$

\section{Conclusion}

Microparticles loaded with methylprednisolone were successfully formulated by spray-drying, and were then characterized and assessed in vitro. Microparticles were produced using biodegradable excipients, including albumin, chondroitin sulfate, and hyaluronic acid, thereby mimicking the properties of the extracellular structure of cartilage matrix. These microparticles may have applications in cartilage tissue engineering if developed for intra-articular injection in inflammatory pathologies like arthritis. The best outcomes were obtained with microparticles containing methylprednisolone $9.1 \%$, which had an encapsulation efficiency higher 
than $89 \%$ and showed controlled-release behavior, achieving drug release of $80 \%$ in vitro after 25 days. Toxicological assessment shows that these microparticles are biocompatible and do not generate an inflammatory response, and enable cell viability and cell membrane integrity at concentrations lower than $5 \mathrm{mg} / \mathrm{mL}$. This research suggests that methylprednisolone microparticles may become a pharmacological option for the treatment of inflammatory diseases such as arthritis in the future.

\section{Acknowledgments}

The authors would like to thank the Chilean Council for Science and Technology, (CONICYT-FONDECYT) (Project 11080101). B Tobar-Grande is supported by the International Cooperation Agency of Chile (AGCI). Institut Galien ParisSud is a member of the Laboratory of Excellence LERMIT supported by a grant from ANR (ANR-10-LABX-33). We would also like to thank Margarita González and Mario Rodríguez for their fruitful technical discussions concerning this work.

\section{Disclosure}

The authors report no conflicts of interest in this work.

\section{References}

1. Khanna D, Arnold EL, Pencharz JN, et al. Measuring process of arthritis care: the Arthritis Foundation's quality indicator set for rheumatoid arthritis. Semin Arthritis Rheum. 2006;35(4):211-237.

2. Butoescu N, Jordan O, Petri-Fink A, Hofmann H, Doelker E. Co-encapsulation of dexamethasone 21-acetate and SPIONs into biodegradable polymeric microparticles designed for intra-articular delivery. J Microencapsul. 2008;25(5):339-350.

3. Murakami N, Takase H, Saito T, Iwata K, Miura H, Naruse T. Effects of a novel non-steroidal anti-inflammatory drug (M-5011) on bone metabolism in rats with collagen-induced arthritis. Eur J Pharmacol. 1998;352(1):81-90.

4. Yen JH. Treatment of early rheumatoid arthritis in developing countries. Biologics or disease-modifying anti-rheumatic drugs? Biomed Pharmacother. 2006;60(10):688-692.

5. Lundberg IE, Grundtman C, Larsson E, Klareskog L. Corticosteroids from an idea to clinical use. Best Pract Res Clin Rheumatol. 2004;18(1):7-19.

6. Barnes PJ. Molecular mechanisms and cellular effects of glucocorticosteroids. Immunol Allergy Clin North Am. 2005;25(3): 451-468.

7. Schumacher HR, Chen LX. Injectable corticosteroids in treatment of arthritis of the knee. Am J Med. 2005;118(11):1208-1214.

8. Walker-Bone K, Javaid K, Arden N, Cooper C. Regular review: medical management of osteoarthritis. BMJ. 2000;321(7266):936-940.

9. Stevenson CL, Santini JT Jr, Langer R. Reservoir-based drug delivery systems utilizing microtechnology. Adv Drug Deliv Rev. 2012;64(14): 1590-1560.

10. Obeidat WM. Recent patents review in microencapsulation of pharmaceuticals using the emulsion solvent removal methods. Recent Pat Drug Deliv Formul. 2009;3(3):178-192.

11. Butoescu N, Jordan O, Doelker E. Intra-articular drug delivery systems for the treatment of rheumatic diseases: a review of the factors influencing their performance. Eur J Pharm Biopharm. 2009;73(2): 205-218.
12. Cerroni B, Chiessi E, Margheritelli S, Oddo L, Paradossi G. Polymer shelled microparticles for a targeted doxorubicin delivery in cancer therapy. Biomacromolecules. 2011;12(3):593-601.

13. Pranzatelli MR. Innovations in drug delivery to the central nervous system. Drugs Today (Barc). 1999;35(6):435-448.

14. Butoescu N, Seemayer CA, Foti M, Jordan O, Doelker E. Dexamethasone-containing PLGA superparamagnetic microparticles as carriers for the local treatment of arthritis. Biomaterials. 2009; 30(9):1772-1780.

15. Patel RP, Patel MP, Suthar AM. Spray drying technology: an overview. Indian J Sci Technol. 2009;2(10):44-47.

16. Cruz L, Fattal E, Tasso L, et al. Formulation and in vivo evaluation of sodium alendronate spray-dried microparticles intended for lung delivery. J Control Release. 2011;152(3):370-375.

17. Rattes ALR, Oliveira WP. Spray drying conditions and encapsulating composition effects on formation and properties of sodium diclofenac microparticles. Powder Technology. 2007;171:7-14.

18. Wang AJ, Lu YP, Zhu RF, Li ST, Ma XL. Effect of process parameters on the performance of spray dried hydroxyapatite microspheres. Powder Technology. 2009;191:1-6.

19. Barba AA, D'amore M, Cascone S, Lamberti A, Titomanlio G. Intensification of biopolymeric microparticles production by ultrasonic assisted atomization. Chem Eng Process. 2010;48:1475-1481.

20. Cascone S, Lamberti G, Titomanlio G, Barba AA, d'Amore M. Microencapsulation effectiveness of small active molecules in biopolymer by ultrasonic atomization technique. Drug Dev Ind Pharm. 2012;38(12):1486-1493.

21. Dalmoro A, Barba AA, Lamberti G, d'Amore M. Intensifying the microencapsulation process: ultrasonic atomization as an innovative approach. Eur J Pharm Biopharm. 2012;80(3):471-477.

22. Mansour HM, Sohn M, Al-Ghananeem A, Deluca PP. Materials for pharmaceutical dosage forms: molecular pharmaceutics and controlled release drug delivery aspects. Int J Mol Sci. 2010;11(9): 3298-3322.

23. Urs AVR, Kavitha K, Sockan GN. Albumin microspheres: an unique system as drug delivery carriers for non steroidal anti-inflammatory drugs (NASIDs). Int J Pharm Sci Rev Res. 2010;5(2):10-17.

24. Kafedjiiski K, Jetti RK, Foger F, et al. Synthesis and in vitro evaluation of thiolated hyaluronic acid for mucoadhesive drug delivery. Int $J$ Pharm. 2007;343(1-2):48-58.

25. Sui W, Huang L, Wang J, Bo Q. Preparation and properties of chitosan chondroitin sulfate complex microcapsules. Colloids Surf B Biointerfaces. 2008;65(1):69-73.

26. Pecchi E, Priam S, Mladenovic Z, et al. A potential role of chondroitin sulfate on bone in osteoarthritis: inhibition of prostaglandin E and matrix metalloproteinases synthesis in interleukin-1beta-stimulated osteoblasts. Osteoarthritis Cartilage. 2012;20(2):127-135.

27. Oerther S, Payan E, Lapicque F, et al. Hyaluronate-alginate combination for the preparation of new biomaterials: investigation of the behaviour in aqueous solutions. Biochim Biophys Acta. 1999;1426(1): 185-194.

28. Katta J, Jin Z, Ingham E, Fisher J. Chondroitin sulphate: an effective joint lubricant? Osteoarthritis Cartilage. 2009;17(8):1001-1008.

29. Gomez-Gaete C, Tsapis N, Silva L, et al. Supramolecular organization and release properties of phospholipid-hyaluronan microparticles encapsulating dexamethasone. Eur J Pharm Biopharm. 2008; 70(1):116-126.

30. Zhang Z, Park Y, Kemp MM, et al. Liquid chromatography-mass spectrometry to study chondroitin lyase action pattern. Anal Biochem 2009;385(1):57-64.

31. Kroll A, Pillukat MH, Hahn D, Schnekenburger J. Current in vitro methods in nanoparticle risk assessment: limitations and challenges. Eur J Pharm Biopharm. 2009;72(2):370-377.

32. Kim DH, Lee SH, Kim KN, Kim WM, Shim IB, Lee YK. Cytotoxicity of ferrite particles by MTT and agar diffusion methods for hyperthermic application. J Magn Magn Mater. 2005;293: $287-292$. 
33. Fotakis G, Timbrell JA. In vitro cytotoxicity assays: comparison of LDH, neutral red, MTT and protein assay in hepatoma cell lines following exposure to cadmium chloride. Toxicol Lett. 2006;160(2):171-177.

34. Biggs DL, Lengsfeld CS, Hybertson BM, Ng KY, Manning MC, Randolph TW. In vitro and in vivo evaluation of the effects of PLA microparticle crystallinity on cellular response. $J$ Control Release. 2003;92(1-2):147-161.

35. Han X, Gelein R, Corson N, et al. Validation of an LDH assay for assessing nanoparticle toxicity. Toxicology. 2011;287(1-3):99-104.

36. Jones CF, Grainger DW. In vitro assessments of nanomaterial toxicity. Adv Drug Deliv Rev. 2009;61(6):438-456.

37. Surendrakumar K, Martyn GP, Hodgers EC, Jansen M, Blair JA. Sustained release of insulin from sodium hyaluronate based dry powder formulations after pulmonary delivery to beagle dogs. J Control Release. 2003;91(3):385-394.

38. Kim SJ, Hahn SK, Kim MJ, Kim DH, Lee YP. Development of a novel sustained release formulation of recombinant human growth hormone using sodium hyaluronate microparticles. $J$ Control Release. 2005;104(2):323-335.

39. Walton DE, Mumford CJ. The morphology of spray-dried particles: the effect of process variables upon the morphology of spray-dried particles. Chem Eng Res Des. 1999;77(5):442-460.

40. Baldinger A, Clerdent L, Rantanen J, Yang M, Grohganz H. Quality by design approach in the optimization of the spray-drying process. Pharm Dev Technol. 2012;17(4):389-397.

41. Cilurzo F, Selmin F, Minghetti P, Montanari L. Design of methylprednisolone biodegradable microspheres intended for intra-articular administration. AAPS Pharm Sci Tech. 2008;9(4):1136-1142.

42. Huang $\mathrm{S}, \mathrm{Fu} \mathrm{X}$. Cell behavior on microparticles with different surface morphology. J Alloys Compd. 2010;493(1-2):246-251.

43. Vehring R. Pharmaceutical particle engineering via spray drying. Pharm Res. 2008;25(5):999-1022.

44. Tewa-Tagne P, Briancon S, Fessi H. Spray-dried microparticles containing polymeric nanocapsules: formulation aspects, liquid phase interactions and particles characteristics. Int J Pharm. 2006;325(1-2):63-74.

45. Gervelas C, Serandour AL, Geiger S, et al. Direct lung delivery of a dry powder formulation of DTPA with improved aerosolization properties: effect on lung and systemic decorporation of plutonium. $J$ Control Release. 2007;118(1):78-86.

46. Simonoska-Crcarevska M, Glavas-Dodov M, Goracinova K. Chitosan coated $\mathrm{Ca}$-alginate microparticles loaded with budesonide for delivery to the inflamed colonic mucosa. Eur J Pharm Biopharm. 2008; 68(3):565-578.
47. Fajardo AR, Piai JF, Rubira AF, Muniz EC. Time- and pH-dependent self-rearrangement of a swollen polymer network based on polyelectrolytes complexes of chitosan/chondroitin sulfate. Carbohydr Polym. 2010;80:934-943

48. Guillory JK. Heats of transition of methylprednisolone and sulfathiazole by a differential thermal analysis method. J Pharm Sci. 1967; 56(1):72-76.

49. Sui X, Wei W, Yang L, et al. Preparation, characterization and in vivo assessment of the bioavailability of glycyrrhizic acid microparticles by supercritical anti-solvent process. Int J Pharm. 2012;423(2): 471-479.

50. Yesil-Celiktas O, Cetin-Uyanikgil EO. In vitro release kinetics of polycaprolactone encapsulated plant extract fabricated by supercritical antisolvent process and solvent evaporation method. J Supercrit Fluids. 2012;62:219-225.

51. Garcia-Martinez O, Diaz-Rodriguez L, Rodriguez-Perez L, De Luna-Bertos E, Reyes Botella C, Ruiz CC. Effect of acetaminophen, ibuprofen and methylprednisolone on different parameters of human osteoblast-like cells. Arch Oral Biol. 2011;56(4):317-323.

52. Caron JP. Intra-articular injections for joint disease in horses. Vet Clin North Am Equine Pract. 2005;21(3):559-573.

53. Campos E, Cordeiro R, Santos AC, Matos C, Gil MH. Design and characterization of bi-soft segmented polyurethane microparticles for biomedical application. Colloids Surf B Biointerfaces. 2011;88(1):477-482.

54. Marti L, Moreno A, Filella X, et al. Cytokines value as a sepsis and mortality predictor in elderly patients with fever. Med Clin (Barc). 2003;121(10):361-366. Spanish.

55. Jose Leon A, Garrote JA, Arranz E. Cytokines in the pathogenesis of inflammatory bowel diseases. Med Clin (Barc). 2006;127(4):145-152. Spanish.

56. Campo GM, Avenoso A, D'Ascola A, et al. Hyaluronan in part mediates IL-1 beta-induced inflammation in mouse chondrocytes by up-regulating CD44 receptors. Gene. 2012;494(1):24-35.

57. Torkildsen O, Vedeler CA, Ulvestad E, Aarseth JH, Nyland HI, Myhr KM. High dose methylprednisolone induces FcyRI on granulocytes in MS-patients. J Neuroimmunol. 2005;167(1-2):138-142.

58. Yoshida N, Yoshikawa T, Nakamura Y, et al. Methylprednisolone inhibits neutrophil-endothelial cell interactions induced by interleukin-1 beta under flow conditions. Life Sci. 1997;60(25):2341-2347.
International Journal of Nanomedicine

\section{Publish your work in this journal}

The International Journal of Nanomedicine is an international, peerreviewed journal focusing on the application of nanotechnology in diagnostics, therapeutics, and drug delivery systems throughout the biomedical field. This journal is indexed on PubMed Central, MedLine, CAS, SciSearch ${ }^{\circledR}$, Current Contents ${ }^{\circledR} /$ Clinical Medicine,

\section{Dovepress}

Journal Citation Reports/Science Edition, EMBase, Scopus and the Elsevier Bibliographic databases. The manuscript management system is completely online and includes a very quick and fair peer-review system, which is all easy to use. Visit http://www.dovepress.com/ testimonials.php to read real quotes from published authors. 